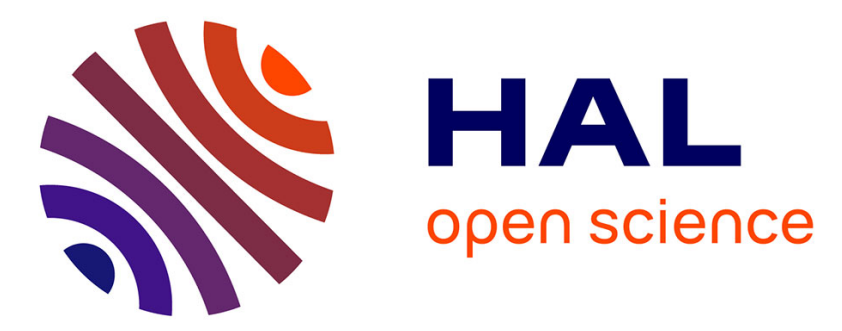

\title{
Effects of a strain rate sensitive material on the optimization of an hydroforming process
}

Cunsheng Zhang, Lionel Leotoing, Dominique Guines, Eric Ragneau

\section{To cite this version:}

Cunsheng Zhang, Lionel Leotoing, Dominique Guines, Eric Ragneau. Effects of a strain rate sensitive material on the optimization of an hydroforming process. International Journal of Material Forming, 2008, pp.335-338. 10.1007/s12289-008-0063-7 . hal-01027761

\section{HAL Id: hal-01027761 \\ https://hal.science/hal-01027761}

Submitted on 22 Jul 2014

HAL is a multi-disciplinary open access archive for the deposit and dissemination of scientific research documents, whether they are published or not. The documents may come from teaching and research institutions in France or abroad, or from public or private research centers.
L'archive ouverte pluridisciplinaire HAL, est destinée au dépôt et à la diffusion de documents scientifiques de niveau recherche, publiés ou non, émanant des établissements d'enseignement et de recherche français ou étrangers, des laboratoires publics ou privés. 


\title{
Effects of a strain rate sensitive material on the optimization of an hydroforming process
}

\author{
C. Zhang, L. Leotoing, D. Guines, E. Ragneau
}

\author{
INSA de Rennes - LGCGM - 20 avenue des Buttes de Coёsmes 35043 Rennes Cedex, France \\ e-mail: lionel.leotoing@insa-rennes.fr
}

\begin{abstract}
The hydroforming process of a T-tube is simulated with the finite element code ABAQUS. The influence of the internal pressure and the axial displacement levels on the final tube quality is evaluated through a "process diagram". Due to the strain rate range observed during the process, the strain rate sensitivity of the material is considered for the determination of the forming limit curves and for simulation of the process. Theoretical and numerical evaluation of the forming limit curves shows that formability increase with the strain rate sensitivity coefficient $m$. The determination of the process diagram for a higher value of $m$ emphasizes that the forming zone (tube with zero defect) significantly grows. The optimization of hydroforming process is very sensitive to forming limit curves identification and the effects of strain rate on formability must be accurately quantified.
\end{abstract}

KEYWORDS: Hydroforming, Strain rate sensitivity, Forming Limit Curves (FLC)

\section{INTRODUCTION}

Hydroforming is an innovative sheet metal forming process which receives more and more consideration in industry, especially in automotive and aeronautics. Many process parameters like pressure, tool displacements, temperature or strain rate can play a significant role on the final shape and quality of hydroformed parts. In order to obtain complex parts with small operational tolerance, the optimization of the hydroforming process must include the effects of these process parameters.

For the evaluation of sheet material formability, the forming limit diagrams (FLDs), introduced by Keeler and Backofen in the 1960s [4], remain a very used tool in spite of some shortcomings. Few authors have studied the effects of material strain rate sensitivity on this formability. However, strain rate sensitivity has been experimentally identified as an important factor for determining formability of sheet metal and can alter substantially the level and shape of FLDs [7, 2]. The theoretical M-K model has been used by Hutchinson et al. [3] to predict the FLDs with Von Mises yield function, by taking into account rate sensitivity. Their work has made important contributions to gaining insight into the roles of constitutive equations and plasticity theories on FLDs. Barata De Rocha et al. [1] predicted the strain path-dependent FLDs by considering the strain rate sensitivity using Hill's theory of plastic anisotropy. Nie and Lee [6] calculated the FLDs for strain rate sensitive materials by applying the isotropic hardening model of the flow theory for the anisotropic sheet metals. In these studies, left-hand side of the FLDs, because of the complex algorithms and lengthy calculations, has received little attention. Moreover, the theoretical results strongly depend on the model of the viscoplastic law and on the imperfection factor of the M-K model. Numerically, the strain rate sensitivity on the evaluation of FLDs by finite element method has never been considered.

The aim of this study is to evaluate the influence of pressure and axial displacement on the quality of a T-tube by plotting a so-called "process diagram". Then, the evolution of this process diagram with the increase of the strain rate is presented for a sensitive material. Before, the analytical and numerical influence of strain rate on formability for the chosen viscoplastic law is quantified in the first part. 


\section{STRAIN RATE SENSITIVITY ON FORMA- BILITY}

\subsection{Viscoplastic law for study}

The material is described by an isotropic work hardening law, the multiplicative Swift law :

$$
\bar{\sigma}^{k}=K\left(\bar{\varepsilon}_{0}+\bar{\varepsilon}^{k}\right)^{n}\left(\dot{\bar{\varepsilon}}^{k}\right)^{m}
$$

where $\bar{\sigma}^{k}$ is the equivalent stress, $\bar{\varepsilon}^{k}$ and $\dot{\varepsilon}^{k}$ are respectively equivalent plastic strain and equivalent plastic strain rate. $K$ and $\bar{\varepsilon}_{0}$ are material parameters, while $n$ and $m$ are the strain hardening and strain rate sensitivity coefficients. For the studied aluminium alloy, the value of these parameters are given in Table 1 .

Table 1: Swift parameters

\begin{tabular}{ccc}
\hline$K(M P a)$ & $\bar{\varepsilon}_{0}$ & $n$ \\
\hline 438.8 & 0.008 & 0.22 \\
\hline
\end{tabular}

For the strain rate sensitivity coefficient $m$, two different values are considered in the following parametric study ( $m=0$ and $m=0.04$ ).

\subsection{Forming Limit Diagram}

Two different approaches are used to determine the whole forming limit diagram for the considered material. The first one is theoretical, a Newton-Raphson algorithm based on the M-K model is developed and the limit strains for various load paths are performed. For the left-hand side of the FLD, the minimal limit strain is found by adjusting the groove inclination of the $\mathrm{M}-\mathrm{K}$ model.

In the second approach, a marciniak test is simulated with the commercially available finite element code ABAQUS. Different specimen geometries are tested for the determination of the different strain states, ranging from uniaxial traction to biaxial. The constitutive law (Eq. 1) is implemented by using the UHARD user subroutine. The onset of local necking, which characterize the limit of the formability, is detected by identifying the bifurcation point corresponding to the occurrence of a plastic instability.

The theoretical and numerical forming limit curves are plotted for the two values of $m$ (Figure 1).

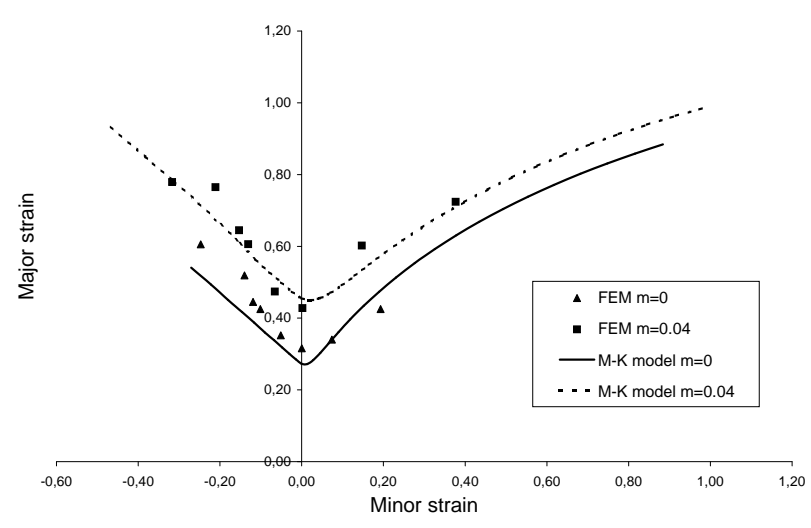

Figure 1: Theoretical and numerical forming limit curves for $m=0$ and $m=0.04$

In the M-K model, the value of the initial imperfection factor is chosen to make the best fit between the theoretical model and the numerical one for a given punch speed $(5 \mathrm{~m} / \mathrm{s}$ which leads to an equivalent plastic strain rate close to $100 \mathrm{~s}^{-1}$ ). For the studied material, the ratio between thickness of weak zone and sheet thickness is set to 0.9985 for $m=0$. By keeping this same value of imperfection, the FLD with a higher strain rate sensitive material $(m=0.04)$ is evaluated with the two models. In Figure 1, a good agreement between the numerical and theoretical methods for $m=0$ and $m=0.04$ is observed. Clearly, the strain rate sensitivity has an important influence on the level of the forming limit curve. The same tendency is observed with the numerical and theoretical approaches, the increase of the strain rate sensitivity coefficient improves the formability of the modelled material.

\section{HYDROFORMED T-TUBE}

\subsection{Finite element model}

To illustrate this strain rate sensitivity effects on formability, the hydroforming process of the classical T-tube [5] is modelled. Figure 2 presents the geometrical characteristics of the tube. The initial thickness of the sheet metal is $1.02 \mathrm{~mm}$. 


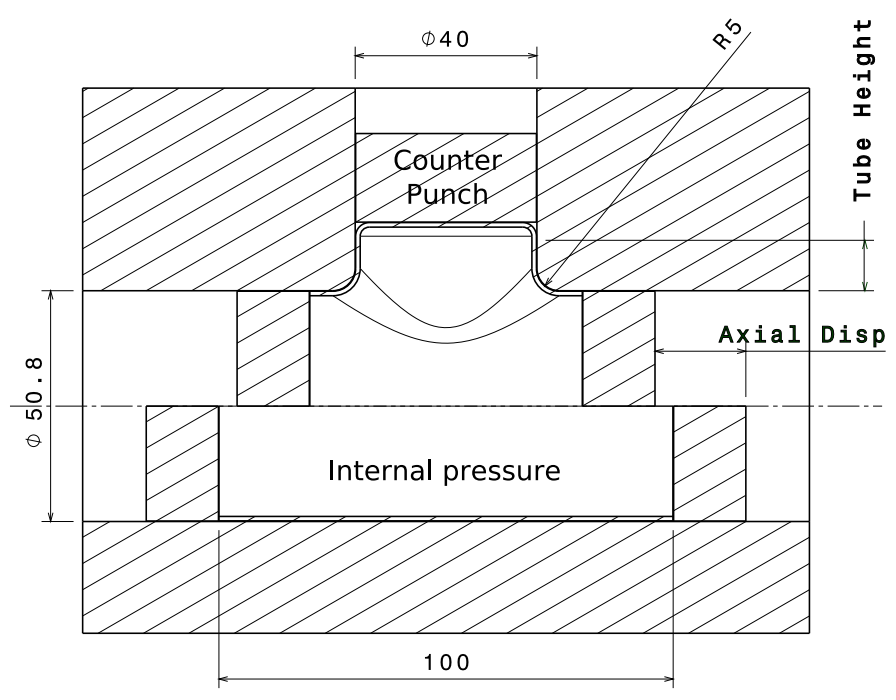

Figure 2: Geometrical characteristics of the hydroformed T-tube

Due to the geometry of the problem, only one quarter of the part is simulated. Three process parameters are controlled by the finite element simulation : the axial displacement (Axial Disp in Figure 2), the internal pressure and the counter punch displacement. The evolution of these three process parameters during hydroforming cycle is given in Figure 3.

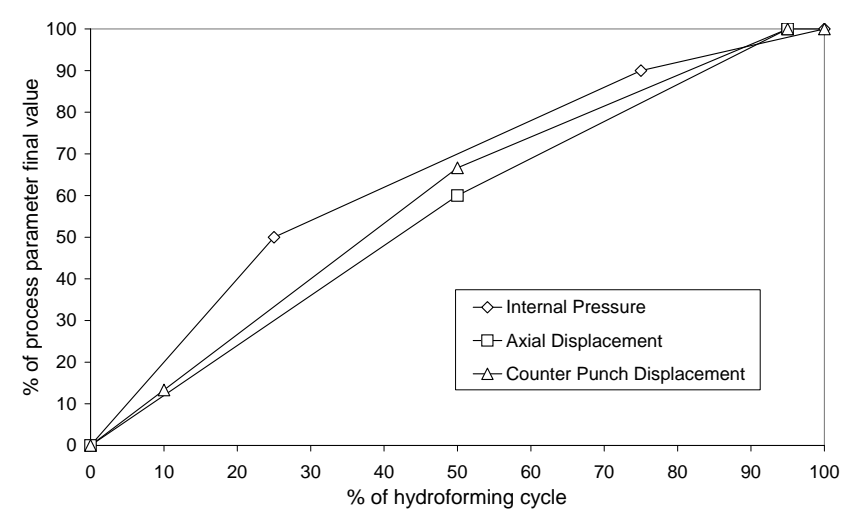

Figure 3: Evolution of the process parameters during hydroforming cycle

The analysis is carried out with shell linear elements S4R. The elasticity of the tube is defined with a Young's modulus of 70000 MPa and a Poisson's ratio of 0.3. The same constitutive law (1) and the same rheological parameter values (Table 1) as used for determining Forming Limit Diagram are implemented in ABAQUS. The contact interaction between tube and dies is modeled using Coulomb law with a friction coefficient of 0.05 .

\subsection{Tube defects}

Four different defects are considered for the evaluation of the simulated hydroformed part quality :

- the non-respect of the forming limit curves (FLC Def)

- the tube height (Figure 2) must be equal or greater than $10 \mathrm{~mm}$ and along this height, the lack of cylindricity must be less than $1 \%$ - (CYL Def)

- the thinning down of final sheet thickness must be less than $12 \%$ of the initial one - (STH Def)

- the appearance of wrinkling (local instability) (WRK Def)

\section{RESULTS AND DISCUSSION}

\subsection{Process diagram}

The parametric study is performed with two process parameters : the axial displacement and the internal pressure. The total displacement of the counter punch is fixed to $15 \mathrm{~mm}$. In Figure 4, the process diagram presents the evaluation of the tube quality when modifying the maximal value of axial displacement and internal pressure (Figure 3 ) for a zero strain rate sensitivity coefficient value $(m=0)$.

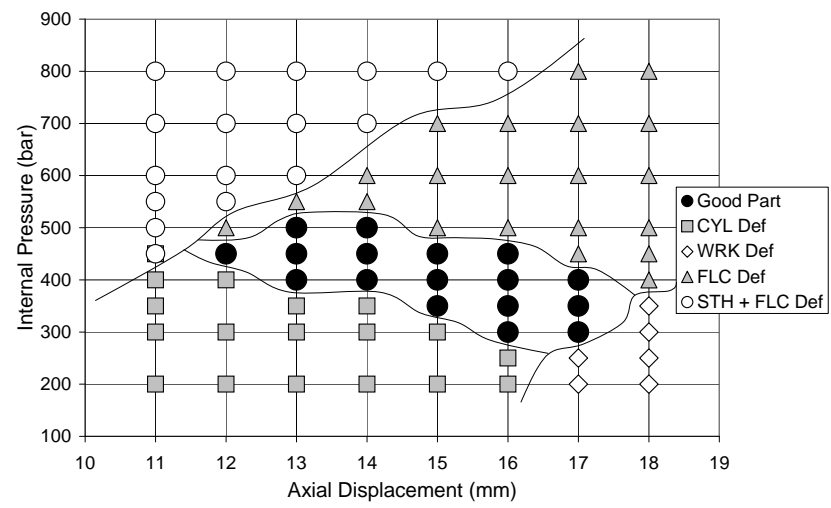

Figure 4: Process diagram of the tube for $m=0$ 
For an axial displacement varying from $11 \mathrm{~mm}$ to $18 \mathrm{~mm}$ and for internal pressure from 200bar to $800 b a r$, five different zones are clearly represented in Figure 4. A compromise between pressure and displacement must be reached in order to obtain good parts, this is the so-called "forming zone". When the pressure is too high, strain components may be higher than forming limit strains or final sheet thickness may be too small. For a small pressure and an important axial displacement, local instabilities (wrinkling) appear near the radius $R 5$ (Figure 2) of the T-Tube.

\subsection{Strain rate sensitivity}

The same parametric study is performed with a strain rate sensitivity coefficient value of 0.04 . As presented in Figure 1, the forming limit curve is updated and the average strain rate observed during simulation is close to $100 s^{-1}$.

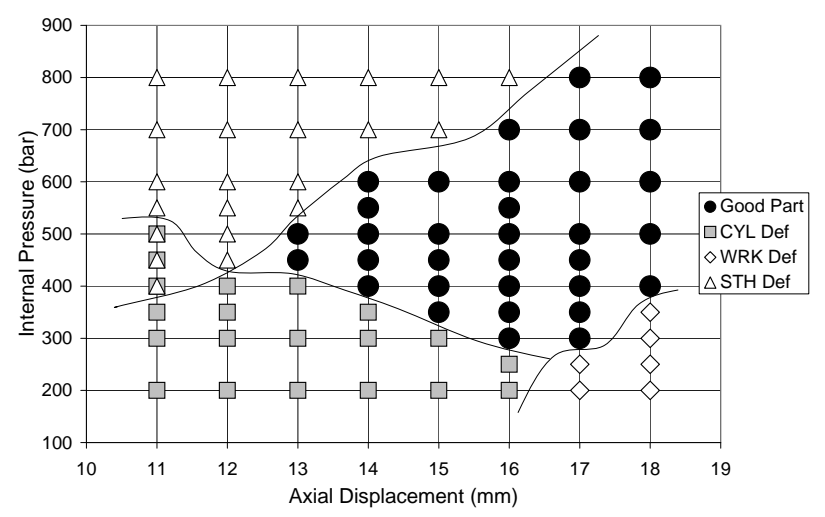

Figure 5: Process diagram of the tube for $m=0.04$

In Figure 5, the forming zone has significantly grown for this value of $m$. Consequently, the final choice of the two process parameter values is extended. The main interest consists in the forming of more complex parts as illustrated in Figure 6. In this figure, the minimal tube height $(10 \mathrm{~mm}$ in the previous case) is fixed to $12 \mathrm{~mm}$ and one can see that the forming zone is clearly reduced. The plotting of the process diagram without taking into account strain rate sensitivity shows that no value of internal pressure and axial displacement permits to obtain good parts.

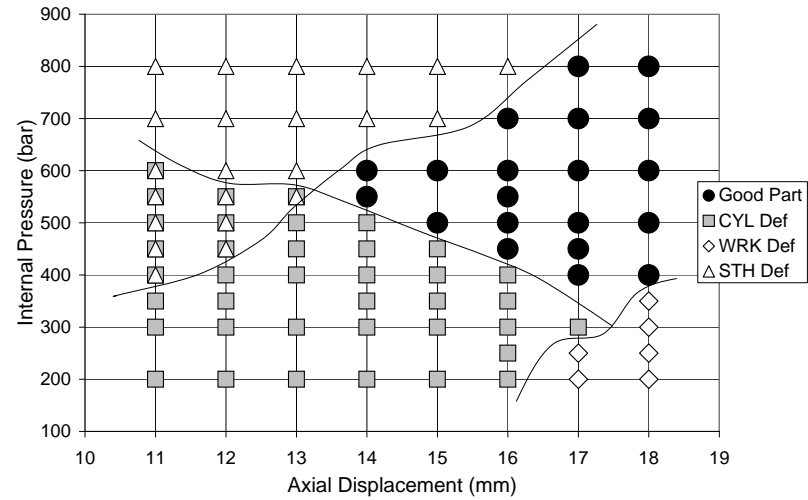

Figure 6: Process diagram of the tube for $m=0.04$ and for a minimal tube height of $12 \mathrm{~mm}$

\section{CONCLUSIONS}

The hydroforming process simulation of a T-tube permits to plot a process diagram with and without a strain rate sensitivity of the material. This paper clearly underlines that the optimization of the process parameters needs an accurate prediction of the forming limit curves which level and shape seem to be very sensitive to strain rate. At the present time, experimental investigations of strain rate effects on sheet formability are in progress.

\section{REFERENCES}

[1] A. Barata Da Rocha, F. Barlat, and J.M. Jalinier. Prediction of the fld of anisotropic sheets in linear and non-linear loading. Materials science and engineering, 68:151-164, 1984-1985.

[2] P. Broomhead and R.J. Grieve. The effect of strain rate on the strain to fracture of a sheet steel under biaxial tensile stress conditions. Journal of engineering materials and technology, 104:102-106, 1982.

[3] J.W. Hutchinson and K.W. Neale. Sheet necking-iii strainrate effect. Mechanics of sheet metal forming, pages 269$285,1978$.

[4] S.P. Keeler and W.A. Backofen. Forming limit diagrams. Trans. ASM, 56:25-28, 1963.

[5] M. Koç and T. Altan. An overall review of the tube hydroforming (THF) technology. Journal of Materials Processing Technology, 108:384-393, 2001.

[6] Q.Q. Nie and D. Lee. The effect of rate-sensitivity on history dependent forming limit of anisotropic sheet metals. Journal of materials shaping technology, 9:233-240, 1991.

[7] J.H. Percy. The effect of strain rate on the fld for sheet metal. Annals of the CIRP, 29:151-152, 1980. 